\title{
Theoretical Study of the $\pi$-Bridge Influence with Different Units of Thiophene and Thiazole in Coumarin Dye-Sensitized Solar Cells
}

\author{
Rody Soto-Rojo, ${ }^{1,2}$ Jesús Baldenebro-López, ${ }^{2}$ and Daniel Glossman-Mitnik ${ }^{1}$ \\ ${ }^{1}$ Laboratorio Virtual NANOCOSMOS, Centro de Investigación en Materiales Avanzados S.C., Miguel de Cervantes 120, \\ Complejo Industrial Chihuahua, 31136 Chihuahua, CHIH, Mexico \\ ${ }^{2}$ Facultad de Ingeniería Mochis, Universidad Autónoma de Sinaloa, Prol. Ángel Flores y Fuente de Poseidón S/N, \\ 81223 Los Mochis, SIN, Mexico
}

Correspondence should be addressed to Daniel Glossman-Mitnik; daniel.glossman@cimav.edu.mx

Received 10 October 2015; Accepted 21 December 2015

Academic Editor: K. R. Justin Thomas

Copyright (C) 2016 Rody Soto-Rojo et al. This is an open access article distributed under the Creative Commons Attribution License, which permits unrestricted use, distribution, and reproduction in any medium, provided the original work is properly cited.

\begin{abstract}
Eight coumarin derivative dyes were studied by varying the $\pi$-bridge size with different thiophene and thiazole units for their potential use in dye-sensitized solar cells (DSSC). Geometry optimization, the energy levels and electron density of the Highest Occupied Molecular Orbital and the Lowest Unoccupied Molecular Orbital, and ultraviolet-visible absorption spectra were calculated by Density Functional Theory (DFT) and Time-Dependent-DFT. All molecular properties were analyzed to decide which dye was the most efficient. Furthermore, chemical reactivity parameters, such as chemical hardness, electrophilicity index, and electroaccepting power, were obtained and analyzed, whose values predicted the properties of the dyes in addition to the rest of the studied molecular properties. Our calculations allow us to qualitatively study dye molecules and choose the best for use in a DSSC. The effects of $\pi$-bridges based on thiophenes, thiazoles, and combinations of the two were reviewed; dyes with three units mainly of thiazole were chosen as the best photosensitizers for DSSC.
\end{abstract}

\section{Introduction}

The conversion of solar light to electricity through dyesensitized solar cells (DSSC) has been widely studied since the work of O'Regan and Grätzel [1]. DSSC with desirable physical properties, such as transparency and flexibility, high conversion efficiency, and low cost, were achieved using transparent conductor oxide (TCO), $\mathrm{TiO}_{2}$ semiconductors, and $\mathrm{I}^{-} / \mathrm{I}_{3}{ }^{-}$electrolyte [2]. Initially, Ru bipyridyl complexes were studied and showed prominent results, achieving up to $12 \%$ conversion efficiency [3-5]. Metal-free organic dyes were also studied to avoid using $\mathrm{Ru}$, since $\mathrm{Ru}$ is toxic and rare and requires purification [6]. Therefore, organic dyes are more attractive for DSSC because they are cheaper than $\mathrm{Ru}$ based dyes, have controllable absorption wavelengths, allow versatile design, and are easily synthesized [7]. The high conversion efficiencies achieved by metal-free organic dyes have motivated further study. In previous years, Donor- $\pi$ bridge-Acceptor (D- $\pi$-A) dyes have been outstanding DSSC dyes, such as the coumarin derivative dyes with up to $8 \%$ conversion efficiency $[8,9]$ and triphenylamine-based dyes with up to $10 \%$ conversion efficiency [10]; both use thiophenebased groups as the $\pi$-bridge. Recently, D- $\pi$-A organic dyes derivatives of carbazole (ADEKA-1, ADEKA-2, and MK2) and triphenylamine (C257, C258) reached efficiencies of up to $12.8 \%$ using a cobalt(III/II) tris(2,20-bipyridine) complex as the redox electrolyte and thiophene-based groups as the $\pi$-bridge $[11,12]$. Theoretical studies were carried out for a better understanding of the experimental results, mainly about the dye [13-17]. In previous works, it was common to study $\mathrm{D}-\pi$-A dyes using thiophene and its derivatives as $\pi$-conjugated bridges, but the use of thiazole-based groups has also achieved interesting conversion efficiency results in organic solar cells [18] and DSSC [19-21], mainly due 

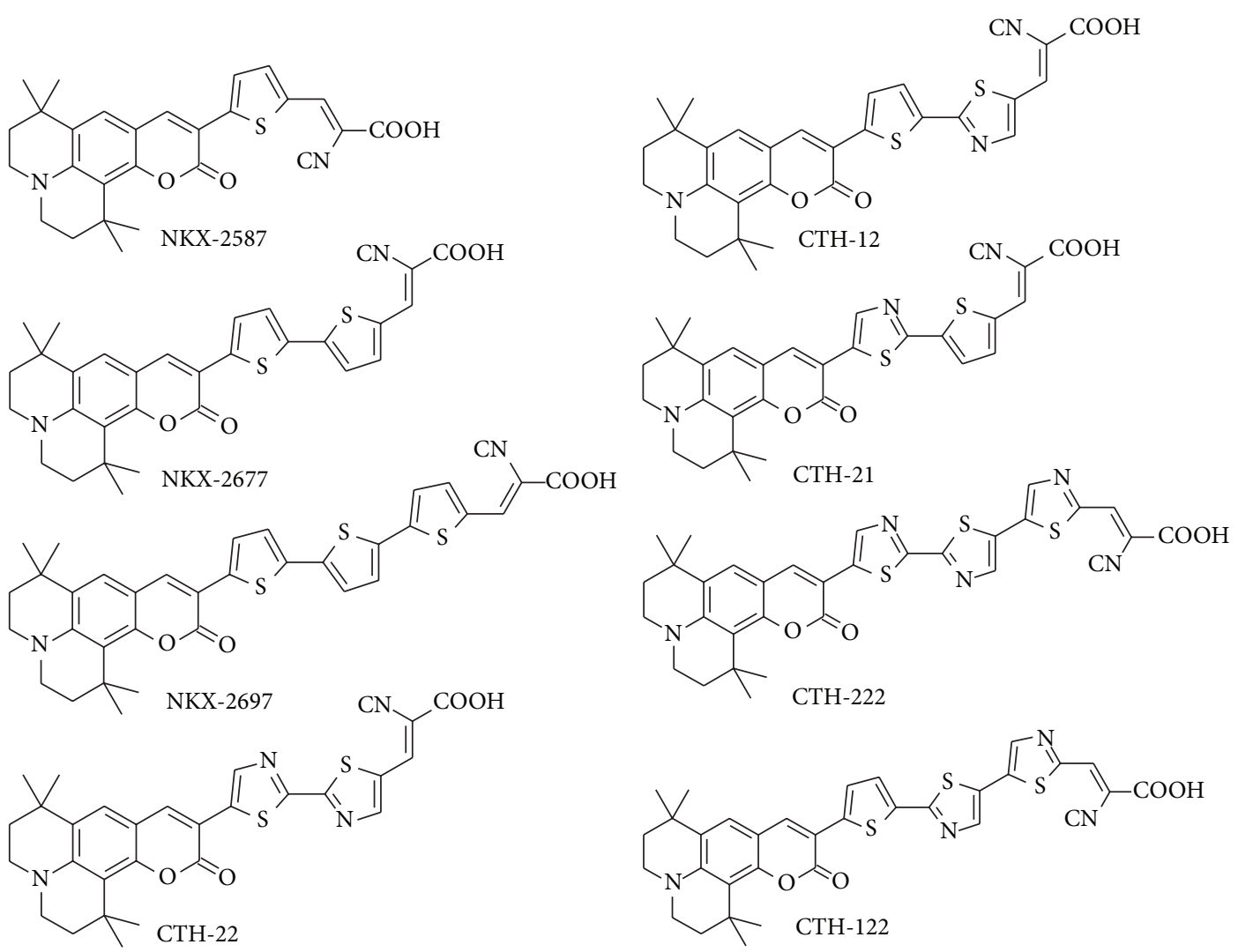

FIGURE 1: Coumarin derivative dye structures.

to the redshift of the maximum absorption wavelength and the improvement of intramolecular charge transfer. Accordingly, we chose eight molecules, shown in Figure 1, with coumarin derivatives as donors and cyanoacrylic acid as acceptors/anchorages while varying the conjugated bridge. Our proposal presents the molecules NKX-2587, NKX-2677, and NKX-2697 that were synthesized and evaluated by Hara et al. [8], which have one, two, and three thiophene units. We also studied five new proposals as sensitizers, CTH-12, CTH-21, CTH-22, CTH-122, and CTH-222, which resulted in conjugated bridges of thiazole groups and the combination of thiazole and thiophene units. The number 1 represents a thiophene unit and the number 2 represents a thiazole unit; for example, CTH-122 is formed from a coumarin derivative (donor), thiophene-thiazole-thiazole, and cyanoacrylic acid (acceptor). The sensitizers were evaluated and compared to using data reported for a $\mathrm{TiO}_{2}$-based DSSC to determine the effect of the $\pi$-bridge. To study this effect from a theoretical point of view, we performed calculations about ultraviolet-visible (UV-Vis) absorption spectra, electronic transitions analysis, energy levels of the Highest Occupied Molecular Orbital (HOMO) and Lowest Unoccupied Molecular Orbital (LUMO), and HOMO and LUMO electrondensity distribution. An important aspect in relation to other studies is the evaluation of the chemical reactivity parameters and their influences on the performance of the dye.

\section{Calculation Details}

This study was performed on the basis of Density Functional Theory (DFT), using the M06 hybrid meta-GGA functional [22] for the ground state geometry optimization and frequencies, the HOMO and LUMO electron density and their energy levels, and the chemical reactivity parameters; the chemical reactivity parameters were obtained by energy calculations (ionic and neutral state) such as those expressed by Parr and Pearson [23] and Gázquez et al. [24]. The M06-2X hybrid meta-GGA functional [22] was used to obtain the UV-Vis absorption spectra in acetonitrile through Time-DependentDFT (TD-DFT) with the nonequilibrium protocol $[25,26]$ and the excitation energies were processed by the SWizard program $[27,28]$ using the Gaussian model to establish the convolution. Both functionals were combined with two basis sets: the $6-31 G(d)[29,30]$ and the 6-311G(d) [31] proposed by Pople. The effect of the solvent was considered by the integral equation formalism polarizable continuum model (IEF-PCM) [32], an implicit method. The difference in energy between the dye's LUMO level and the $\mathrm{TiO}_{2}$ semiconductor conduction band was reviewed, as well as some parameters of chemical reactivity, such as chemical hardness $(\eta)$, electrophilicity index $(\omega)$, and electroaccepting power $\left(\omega^{+}\right)$, to predict the possible behavior of the dye and thus of the DSSC. All computational calculations were carried out with Gaussian 09 Rev. D.01 [33]. 


\section{Results and Discussion}

The maximum absorption wavelengths $\left(\lambda_{\max }\right), \mathrm{HOMO}$ and LUMO energy levels and electron density, and the chemical reactivity are presented to choose the best dye molecule to be employed in a DSSC. M06-2X was the best functional to reproduce the UV-Vis absorption spectra according to the experimental results of NKX-type coumarins reported in the literature $[8,34]$. The selection of the functional is due to the molecule's size, as demonstrated in the theoretical study of charge-transfer excitations in organic dyes by Dev et al. [35]; M06 and M06-2X are two methods from the same family of functionals with different Hartree-Fock exchanges. All calculations were carried out using the 6$31 \mathrm{G}(\mathrm{d})$ and $6-311 \mathrm{G}(\mathrm{d})$ basis sets, with very similar results. Only the HOMO and LUMO energy levels and chemical reactivity are presented with both basis sets; the rest of the results are presented only with the $6-311 \mathrm{G}(\mathrm{d})$ basis set.

3.1. Ultraviolet-Visible Spectra. The absorption maximum wavelength of the eight molecules is around $500 \mathrm{~nm}$, as shown in Figure 2. When the molecular systems contain a thiazole- $\pi$-bridge in their structure, these have a redshift of $\lambda_{\max }$ compared to those with only thiophene groups; the molecules with combined groups (thiazole and thiophene) in the $\pi$-bridge present intermediate $\lambda_{\max }$ between the above; for example, $\lambda_{\max }$ is 509,538 , and $540 \mathrm{~nm}$ for NKX-2697, CTH-122, and CTH-222, respectively. The same behavior is observed for NKX-2677 (501 nm) and CTH-22 (512 nm); the absorption band of the latter is comparable to NKX-2697 (three thiophenes in the $\pi$-bridge).

It is preferable that a photosensitizer's $\lambda_{\max }$ is closer to red and hence has a lower energy gap between the HOMO and LUMO [36], which helps the DSSC to have better charge injection and therefore better efficiency. In this case, the difference among the $\lambda_{\max }$ of all dyes is small, but the CTH222 is slightly better, followed by CTH-122 and NKX-2697; the remaining molecular structures have the following trend: CTH22 > CTH21 $(502 \mathrm{~nm})>$ CTH12 $(501 \mathrm{~nm})>$ NKX-2677 $>$ NKX-2587 $(479 \mathrm{~nm})$. Further, the $\lambda_{\max }$ is more redshifted when the units in the $\pi$-bridge are augmented (thiophenes, thiazoles, or both); this effect already has been reported [37].

Table 1 shows the absorption bands, oscillator strength $(f)$, and electron transitions for each band of the proposed sensitizers; further the experimental maximum absorption wavelengths available in the literature are shown. In the NKX molecules, if the $\pi$-bridge is augmented with a thiophene unit (from NKX-2587 to NKX-2677), the contribution corresponding to the $\lambda_{\max }$ of the HOMO to LUMO decreases by $10 \%$, but $f$ increases by 0.43 ; from NKX-2677 to NKX2697, $f$ increases slightly by 0.02 . In CTH molecules, when the $\pi$-bridge is augmented with a thiazole unit, the HOMOLUMO transition remains around $80 \%$. Furthermore, by using thiazole groups, $f$ decreases by 0.29 from NKX-2677 to CTH-22 and by 0.67 from NKX-2697 to CTH-222. In the case of CTH-12, CTH21, and CTH-122, $f$ decreases, with values of 1.5737, 1.3246, and 1.1430; this affirms the behavior

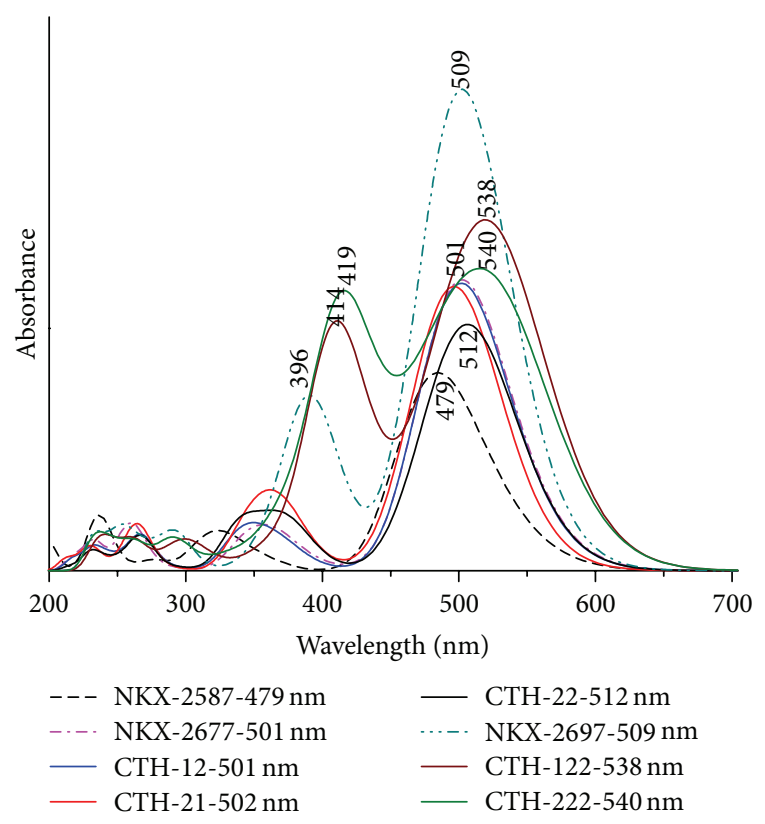

FIgURE 2: Ultraviolet-visible absorption spectra at M06-2X/6$311 G(d)$ level of theory. Acetonitrile was considered as solvent.

of $f$ with the inclusion of thiazole groups. A second band is observed for all molecular systems in the UV-Vis spectrum with a HOMO $\rightarrow \mathrm{LUMO}+1$ transition. The higher values of $f$ for these absorption bands, in order from highest to lowest, correspond to CTH-222, CTH-122, and NKX-2697; the rest of the absorption bands keep a slight variation. The above data suggest that NKX-2697 has higher light harvesting in the HOMO to LUMO transition, followed by NKX-2677 and CTH-21.

3.2. Molecular Orbitals and Energy Levels. The HOMO, HOMO-1, LUMO, and LUMO + 1 energy levels are shown in Figure 3 with the M06 functional and the 6-31G(d) and 6$311 \mathrm{G}(\mathrm{d})$ basis sets. Similar results were achieved between both basis sets, presenting a negative displacement of the energy levels around $0.2 \mathrm{eV}$ from 6-31G(d) to 6-311G(d); however, the tendency of the energy levels among the dyes is maintained, and hence any method can be used adequately. The eight molecules are good photosensitizer candidates because the LUMO level is above the conduction band (CB) of the $\mathrm{TiO}_{2}$ semiconductor $(-4.0 \mathrm{eV})$ [38] and the HOMO level is below the redox potential of the $\mathrm{I}^{-} / \mathrm{I}_{3}{ }^{-}$electrolyte $(-4.8 \mathrm{eV})$ [38], which ensures electron injection from the dye to $\mathrm{TiO}_{2}$ and the regeneration of the dye, obtaining electrons from the electrolyte. In this sense, with both basis sets a more efficient electron transfer using CTH-222 is expected considering the LUMO level, since it is closer to the $\mathrm{TiO}_{2}$ conduction band, followed by CTH-122, CTH-22, and NKX-2697. From the perspective of $\mathrm{LUMO}+1$, a more efficient electron injection is also expected for CTH-222. On the other hand, the best regeneration is obtained when the HOMO level is closer to the redox potential of the electrolyte; thus, the NKX-2697 molecule has the best regeneration. In general, the dyes with 
TABLE 1: Absorption wavelengths, oscillator strengths $(f)$, and the orbitals involved in the transitions of coumarin derivatives using M062X/6-311G(d) and acetonitrile as solvent.

\begin{tabular}{|c|c|c|c|c|}
\hline Molecule & $\lambda(\mathrm{nm})$ & $\lambda_{\exp }(\mathrm{nm})$ & $f$ & Transitions (\%) \\
\hline \multirow{4}{*}{ NKX-2587 } & 479 & \multirow{4}{*}{507} & 1.1686 & $\mathrm{H} \rightarrow \mathrm{L}(91 \%) \mathrm{H}-1 \rightarrow \mathrm{L}(4 \%) \mathrm{H} \rightarrow \mathrm{L}+1(3 \%)$ \\
\hline & 329 & & 0.1718 & $\mathrm{H} \rightarrow \mathrm{L}+1(88 \%) \mathrm{H} \rightarrow \mathrm{L}(2 \%)$ \\
\hline & 312 & & 0.1284 & $\mathrm{H}-1 \rightarrow \mathrm{L}(86 \%) \mathrm{H} \rightarrow \mathrm{L}(4 \%) \mathrm{H}-2 \rightarrow \mathrm{L}+1(3 \%)$ \\
\hline & 236 & & 0.1087 & $\begin{array}{l}\mathrm{H}-1 \rightarrow \mathrm{L}+1(36 \%) \mathrm{H} \rightarrow \mathrm{L}+3(21 \%) \mathrm{H} \rightarrow \mathrm{L}+4(11 \%) \mathrm{H}-4 \rightarrow \mathrm{L} \\
(9 \%) \mathrm{H} \rightarrow \mathrm{L}+3(7 \%) \mathrm{H} \rightarrow \mathrm{L}+5(3 \%) \mathrm{H}-1 \rightarrow \mathrm{L}+3(2 \%)\end{array}$ \\
\hline \multirow{4}{*}{ NKX-2677 } & 501 & \multirow{4}{*}{511} & 1.6028 & $\mathrm{H} \rightarrow \mathrm{L}(81 \%) \mathrm{H}-1 \rightarrow \mathrm{L}(10 \%) \mathrm{H} \rightarrow \mathrm{L}+1(8 \%)$ \\
\hline & 370 & & 0.2034 & $\mathrm{H} \rightarrow \mathrm{L}+1(85 \%) \mathrm{H} \rightarrow \mathrm{L}(5 \%) \mathrm{H} \rightarrow \mathrm{L}+2(4 \%) \mathrm{H}-1 \rightarrow \mathrm{L}(2 \%)$ \\
\hline & 350 & & 0.2098 & $\mathrm{H}-1 \rightarrow \mathrm{L}(80 \%) \mathrm{H} \rightarrow \mathrm{L}(12 \%) \mathrm{H}-3 \rightarrow \mathrm{L}(5 \%)$ \\
\hline & 256 & & 0.1572 & $\begin{array}{l}\mathrm{H}-3 \rightarrow \mathrm{L}(48 \%) \mathrm{H}-5 \rightarrow \mathrm{L}(30 \%) \mathrm{H}-6 \rightarrow \mathrm{L}(5 \%) \mathrm{H}-4 \rightarrow \mathrm{L} \\
(3 \%) \mathrm{H} \rightarrow \mathrm{L}+4(3 \%)\end{array}$ \\
\hline \multirow{4}{*}{ CTH-12 } & 501 & \multirow{4}{*}{-} & 1.5737 & $\mathrm{H} \rightarrow \mathrm{L}(81 \%) \mathrm{H} \rightarrow \mathrm{L}+1(9 \%) \mathrm{H}-1 \rightarrow \mathrm{L}(9 \%)$ \\
\hline & 369 & & 0.2016 & $\mathrm{H} \rightarrow \mathrm{L}+1(82 \%) \mathrm{H} \rightarrow \mathrm{L}+2(7 \%) \mathrm{H} \rightarrow \mathrm{L}(7 \%)$ \\
\hline & 345 & & 0.2391 & $\mathrm{H}-1 \rightarrow \mathrm{L}(82 \%) \mathrm{H} \rightarrow \mathrm{L}(10 \%) \mathrm{H}-2 \rightarrow \mathrm{L}(5 \%)$ \\
\hline & 266 & & 0.1012 & $\begin{array}{l}\mathrm{H}-1 \rightarrow \mathrm{L}+1(35 \%) \mathrm{H}-3 \rightarrow \mathrm{L}(18 \%) \mathrm{H} \rightarrow \mathrm{L}+4(18 \%) \mathrm{H}-2 \rightarrow \mathrm{L} \\
(11 \%) \mathrm{H}-5 \rightarrow \mathrm{L}(4 \%) \mathrm{H} \rightarrow \mathrm{L}+2(3 \%)\end{array}$ \\
\hline \multirow{4}{*}{ CTH-21 } & 502 & \multirow{4}{*}{-} & 1.3246 & $\mathrm{H} \rightarrow \mathrm{L}(83 \%) \mathrm{H}-1 \rightarrow \mathrm{L}(8 \%) \mathrm{H} \rightarrow \mathrm{L}+1(8 \%)$ \\
\hline & 372 & & 0.3792 & $\mathrm{H} \rightarrow \mathrm{L}+1(81 \%) \mathrm{H} \rightarrow \mathrm{L}(9 \%) \mathrm{H} \rightarrow \mathrm{L}+2(6 \%)$ \\
\hline & 351 & & 0.2422 & $\mathrm{H}-1 \rightarrow \mathrm{L}(80 \%) \mathrm{H}-3 \rightarrow \mathrm{L}(7 \%) \mathrm{H} \rightarrow \mathrm{L}(7 \%) \mathrm{H} \rightarrow \mathrm{L}+1(2 \%)$ \\
\hline & 264 & & 0.1401 & $\begin{array}{l}\mathrm{H}-3 \rightarrow \mathrm{L}(38 \%) \mathrm{H}-4 \rightarrow \mathrm{L}(30 \%) \mathrm{H}-1 \rightarrow \mathrm{L}+1(16 \%) \mathrm{H}-2 \rightarrow \mathrm{L} \\
(4 \%)\end{array}$ \\
\hline \multirow{4}{*}{ CTH-22 } & 512 & \multirow{4}{*}{-} & 1.3114 & $\mathrm{H} \rightarrow \mathrm{L}(84 \%) \mathrm{H} \rightarrow \mathrm{L}+1(8 \%) \mathrm{H}-1 \rightarrow \mathrm{L}(7 \%)$ \\
\hline & 374 & & 0.3876 & $\mathrm{H} \rightarrow \mathrm{L}+1(76 \%) \mathrm{H} \rightarrow \mathrm{L}+2(11 \%) \mathrm{H} \rightarrow \mathrm{L}(9 \%)$ \\
\hline & 344 & & 0.2567 & $\begin{array}{l}\mathrm{H}-1 \rightarrow \mathrm{L}(76 \%) \mathrm{H}-3 \rightarrow \mathrm{L}(7 \%) \mathrm{H}-2 \rightarrow \mathrm{L}(6 \%) \mathrm{H} \rightarrow \mathrm{L}(5 \%) \mathrm{H} \\
\rightarrow \mathrm{L}+1(2 \%)\end{array}$ \\
\hline & 267 & & 0.1259 & $\begin{array}{l}\mathrm{H}-3 \rightarrow \mathrm{L}(48 \%) \mathrm{H}-1 \rightarrow \mathrm{L}+1(17 \%) \mathrm{H}-2 \rightarrow \mathrm{L}(8 \%) \mathrm{H}-4 \rightarrow \mathrm{L} \\
(7 \%) \mathrm{H} \rightarrow \mathrm{L}+4(5 \%) \mathrm{H}-10 \rightarrow \mathrm{L}(4 \%)\end{array}$ \\
\hline \multirow{4}{*}{ NKX-2697 } & 509 & \multirow{4}{*}{501} & 1.6247 & $\mathrm{H} \rightarrow \mathrm{L}(71 \%) \mathrm{H}-1 \rightarrow \mathrm{L}(16 \%) \mathrm{H} \rightarrow \mathrm{L}+1(11 \%)$ \\
\hline & 396 & & 0.6693 & $\mathrm{H} \rightarrow \mathrm{L}+1(69 \%) \mathrm{H} \rightarrow \mathrm{L}(14 \%) \mathrm{H} \rightarrow \mathrm{L}+2(12 \%)$ \\
\hline & 382 & & 0.1941 & $\mathrm{H}-1 \rightarrow \mathrm{L}(68 \%) \mathrm{H} \rightarrow \mathrm{L}(14 \%) \mathrm{H}-3 \rightarrow \mathrm{L}(11 \%) \mathrm{H} \rightarrow \mathrm{L}+1(3 \%)$ \\
\hline & 296 & & 0.1079 & $\begin{array}{l}\mathrm{H}-3 \rightarrow \mathrm{L}(52 \%) \mathrm{H}-1 \rightarrow \mathrm{L}(9 \%) \mathrm{H}-6 \rightarrow \mathrm{L}(7 \%) \mathrm{H}-2 \rightarrow \mathrm{L}(6 \%) \\
\mathrm{H}-1 \rightarrow \mathrm{L}+1(6 \%) \mathrm{H} \rightarrow \mathrm{L}+2(5 \%) \mathrm{H}-2 \rightarrow \mathrm{L}+1(3 \%) \mathrm{H}-5 \rightarrow \mathrm{L} \\
(2 \%)\end{array}$ \\
\hline \multirow{4}{*}{ CTH-122 } & 538 & \multirow{4}{*}{-} & 1.1430 & $\mathrm{H} \rightarrow \mathrm{L}(79 \%) \mathrm{H}-1 \rightarrow \mathrm{L}(10 \%) \mathrm{H} \rightarrow \mathrm{L}+1(8 \%)$ \\
\hline & 414 & & 1.0738 & $\begin{array}{l}\mathrm{H} \rightarrow \mathrm{L}+1(59 \%) \mathrm{H} \rightarrow \mathrm{L}(16 \%) \mathrm{H} \rightarrow \mathrm{L}+2(9 \%) \mathrm{H}-1 \rightarrow \mathrm{L}(8 \%) \mathrm{H} \\
-1 \rightarrow \mathrm{L}+1(3 \%)\end{array}$ \\
\hline & 389 & & 0.0549 & $\begin{array}{l}\mathrm{H}-1 \rightarrow \mathrm{L}(62 \%) \mathrm{H} \rightarrow \mathrm{L}+1(15 \%) \mathrm{H}-3 \rightarrow \mathrm{L}(12 \%) \mathrm{H} \rightarrow \mathrm{L}+2 \\
(5 \%) \mathrm{H} \rightarrow \mathrm{L}(4 \%)\end{array}$ \\
\hline & 307 & & 0.0805 & $\begin{array}{l}\mathrm{H}-3 \rightarrow \mathrm{L}(48 \%) \mathrm{H}-5 \rightarrow \mathrm{L}(13 \%) \mathrm{H}-1 \rightarrow \mathrm{L}(12 \%) \mathrm{H}-2 \rightarrow \mathrm{L} \\
(10 \%) \mathrm{H}-2 \rightarrow \mathrm{L}+1(4 \%) \mathrm{H}-1 \rightarrow \mathrm{L}+1(3 \%)\end{array}$ \\
\hline \multirow{4}{*}{ CTH-222 } & 540 & \multirow{4}{*}{-} & 0.9540 & $\mathrm{H} \rightarrow \mathrm{L}(83 \%) \mathrm{H} \rightarrow \mathrm{L}+1(8 \%) \mathrm{H}-1 \rightarrow \mathrm{L}(7 \%)$ \\
\hline & 419 & & 1.1263 & $\begin{array}{l}\mathrm{H} \rightarrow \mathrm{L}+1(58 \%) \mathrm{H} \rightarrow \mathrm{L}(15 \%) \mathrm{H} \rightarrow \mathrm{L}+2(12 \%) \mathrm{H}-1 \rightarrow \mathrm{L}(8 \%) \mathrm{H} \\
-1 \rightarrow \mathrm{L}+1(4 \%)\end{array}$ \\
\hline & 384 & & 0.1283 & $\begin{array}{l}\mathrm{H}-1 \rightarrow \mathrm{L}(60 \%) \mathrm{H}-3 \rightarrow \mathrm{L}(16 \%) \mathrm{H} \rightarrow \mathrm{L}+1(12 \%) \mathrm{H} \rightarrow \mathrm{L}+2 \\
(5 \%) \mathrm{H}-2 \rightarrow \mathrm{L}(2 \%)\end{array}$ \\
\hline & 291 & & 0.0942 & $\begin{array}{l}\mathrm{H}-1 \rightarrow \mathrm{L}+1(65 \%) \mathrm{H}-1 \rightarrow \mathrm{L}(7 \%) \mathrm{H}-3 \rightarrow \mathrm{L}(5 \%) \mathrm{H}-2 \rightarrow \mathrm{L}+ \\
2(4 \%) \mathrm{H} \rightarrow \mathrm{L}+1(3 \%) \mathrm{H}-2 \rightarrow \mathrm{L}(3 \%)\end{array}$ \\
\hline
\end{tabular}

$\lambda_{\text {exp }}=$ experimental maximum absorption wavelength was measured in acetonitrile as solvent.

${ }^{*}$ Lower contributions to $2 \%$ are not shown. 


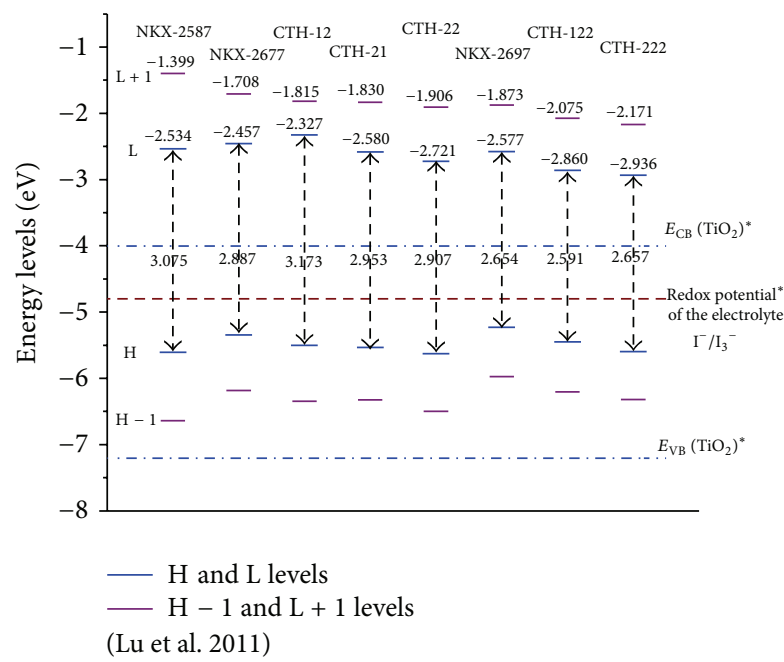

(a)

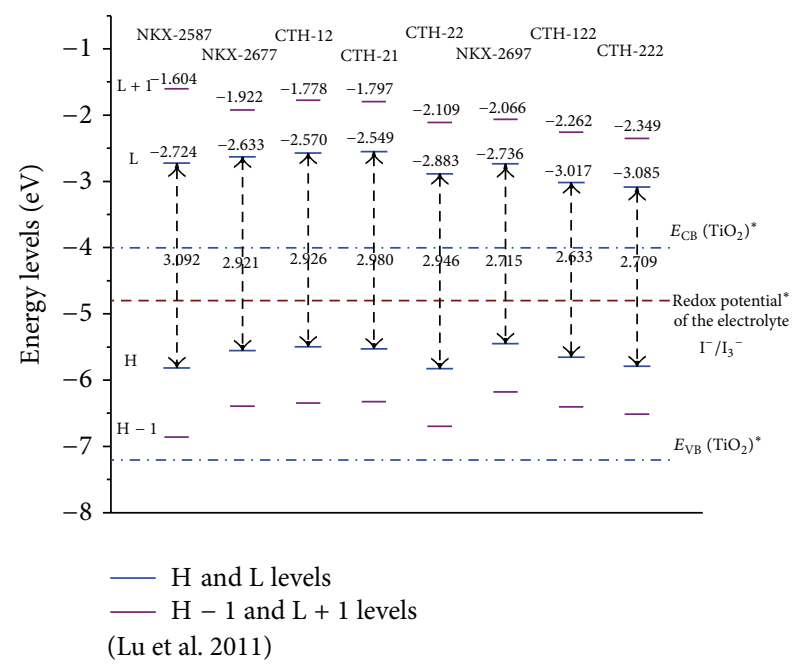

(b)

Figure 3: Molecular orbital energy levels of coumarin derivative dyes using the M06 functional and the basis sets: (a) 6-31G(d) and (b) 6-311G(d).

thiophene units in the $\pi$-bridge have HOMO levels closer to the redox potential than the dyes with thiazole units. With the M06/6-311G(d) level of calculation, the HOMO-LUMO energy gaps have the following trend: CTH-122 < CTH-222 $<$ NKX-2697 < NKX-2677 < CTH-12 < CTH-22 < CTH$21<$ NKX-2587. According to the above and considering that charge injection is the most important parameter in this study, the best dye molecule should be CTH-222 or CTH-122.

The electron densities of the HOMO and LUMO molecular orbitals are shown in Figure 4 at the M06/6-311G(d) level of theory. In this representation, the charge separation is displayed: the HOMO density is concentrated mostly in the electron-donating region (coumarin) and the $\pi$ bridge (thiophene, thiazole, or both), whereas the LUMO density is focused in the $\pi$-bridge and the cyanoacrylic acid acceptor, which is attached to the $\mathrm{TiO}_{2}$ surface. This suggests that the charge separation occurs in the $\pi$-bridge and is more evident when one increases the number of thiophene or thiazole units. Furthermore, the molecules with two units in the $\pi$-bridge do not present differences but the molecules with three thiazole units show good charge separation in the bridge. This good charge separation may promote a more efficient charge transfer from HOMO to LUMO, and hence from LUMO to the $\mathrm{TiO}_{2}$ conduction band [39].

3.3. Chemical Reactivity Study. Using the M06 functional with $6-31 \mathrm{G}(\mathrm{d})$ and $6-311 \mathrm{G}(\mathrm{d})$ basis sets, the molecular energies for the ionic and neutral species were obtained taking into account the gas phase geometry. After that, the chemical reactivity parameters electron affinity $(A)$, ionization potential $(I)$, chemical hardness $(\eta)$, electrophilicity index $(\omega)$, and electroaccepting power $\left(\omega^{+}\right)$were calculated (in $\mathrm{eV}$ ); the values are shown in Table 2. Both levels of calculation
TABLE 2: Chemical reactivity of coumarin-derived dyes using the M06 functional combined with 6-311G(d) basis set.

\begin{tabular}{lccccc}
\hline Molecule & $A$ & $I$ & $\eta$ & $\omega$ & $\omega^{+}$ \\
\hline NKX-2587 & 1.65 & 6.83 & 2.59 & 3.47 & 1.68 \\
NKX-2677 & 1.65 & 6.47 & 2.41 & 3.43 & 1.70 \\
CTH-12 & 1.56 & 6.44 & 2.44 & 3.28 & 1.58 \\
CTH-21 & 1.53 & 6.48 & 2.48 & 3.24 & 1.54 \\
CTH-22 & 1.86 & 6.78 & 2.46 & 3.79 & 1.94 \\
NKX-2697 & 1.78 & 6.31 & 2.27 & 3.61 & 1.87 \\
CTH-122 & 2.00 & 6.54 & 2.27 & 4.01 & 2.16 \\
CTH-222 & 2.06 & 6.70 & 2.32 & 4.13 & 2.23 \\
\hline
\end{tabular}

have good concordance; between the 6-31G(d) and 6-311G(d) basis sets, an average variation in $\mathrm{eV}$ is presented as follows: $0.2 \mathrm{eV}$ for $A, I$, and $\omega^{+}$and $0.3 \mathrm{eV}$ for $\omega$; the $\eta$ parameter does not have a significant variation. For better information analysis, the values of the chemical reactivity parameters with M06/6-311G(d) are represented in Figure 5; electron affinity and ionization potential are not discussed since these are used for obtaining the rest of the parameters and therefore can be redundant. Considering chemical hardness as the resistance to intramolecular charge transfer [23,40], a lower chemical hardness is desired. In Figure 5, $\eta$ decreases while the $\pi$ bridge increases with thiophene or thiazole units, but in dyes with thiophene groups, the $\eta$ is lower than in dyes with thiazole groups.

The dyes NKX-2697 and CTH-122 have the same $\eta$ values $(2.7 \mathrm{eV}), 0.05 \mathrm{eV}$ lower than $\eta$ of CTH-222. NKX-2697 and CTH-122 are proposed as the best dyes for charge transfer and hence a better short circuit current density $\left(J_{\mathrm{SC}}\right)$, which 


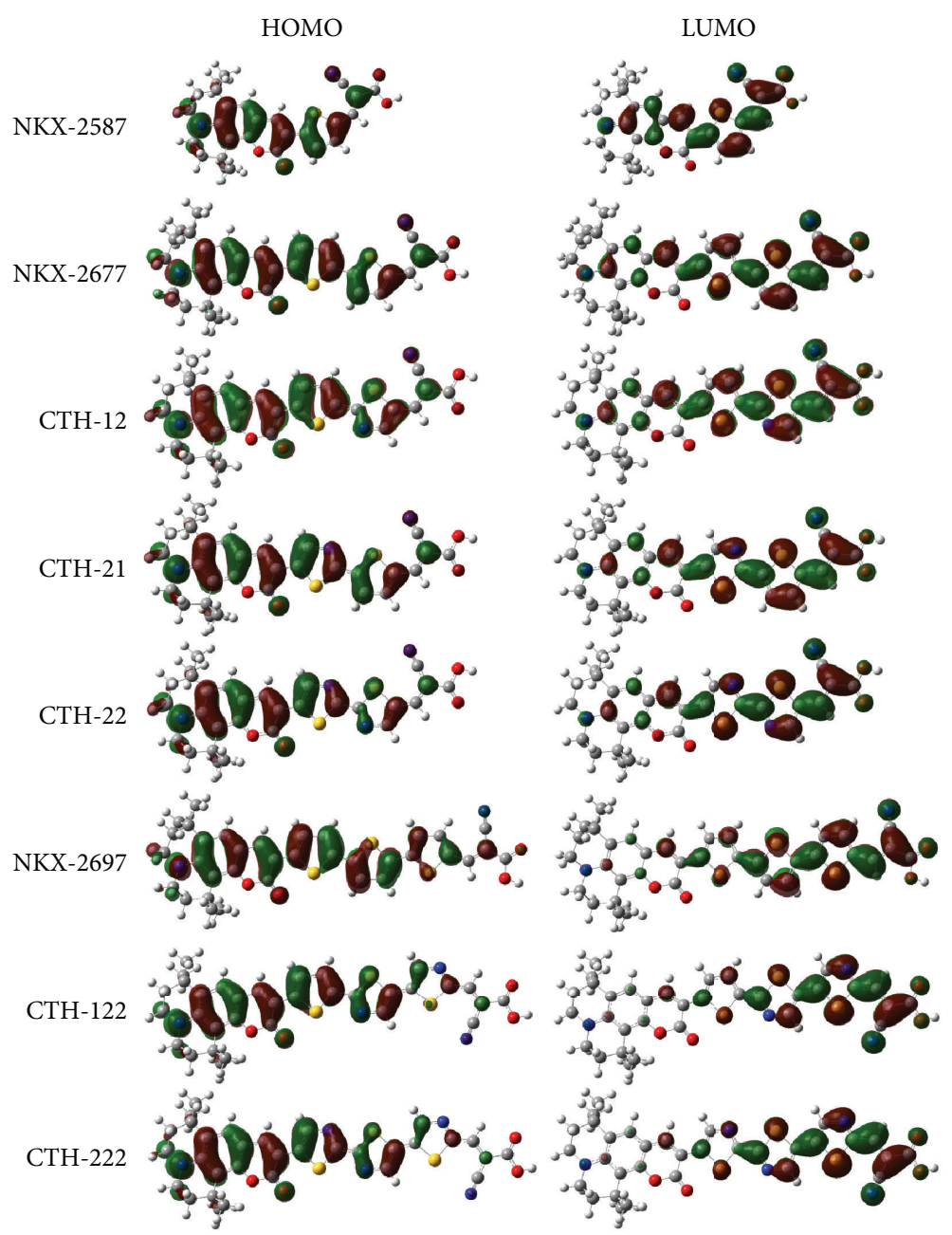

FIGURE 4: HOMO and LUMO molecular orbitals at M06/6-311G(d) level of calculation.

is consistent with the charge separation shown in Figure 4 and a previous study by our group [41]. According to Parr et al. [42], $\omega$ is the measure of the stabilization energy of the molecular system; with the contribution of Gázquez et al. [24], the highest $\omega^{+}$represents the highest electronaccepting ability. With the above in mind, higher $\omega$ and $\omega^{+}$ are desired. CTH-222 has the highest $\omega$ among the coumarin dyes $(4.13 \mathrm{eV})$; this value is $0.12 \mathrm{eV}$ higher than CTH-122 and 0.34 and $0.52 \mathrm{eV}$ greater than CTH-22 and NKX-2697, respectively.

Besides, the $\omega^{+}$presents the same tendency than $\omega$, $\mathrm{CTH}-222$ being the highest with a difference of $0.07 \mathrm{eV}$ in CTH-122, $0.29 \mathrm{eV}$ in CTH-22, and $0.36 \mathrm{eV}$ in NKX-2697. Therefore, CTH-222 has the best stabilization energy and the best electron-withdrawing ability, suggesting that it has the best charge transfer of HOMO to LUMO and therefore we expect convenient $J_{\mathrm{SC}}$ values. Further, CTH-122 presents values very close to CTH-222. As discussed, the previous analysis was performed considering the M06/6-311G(d) level of calculation, but a very similar process can be applied with the $6-31 G(d)$ basis set and reaches the same conclusions. On the other hand, it is more convenient to place the thiophene unit at the beginning of the $\pi$-bridge; for example, CTH-12 has lower $\eta$, higher $\omega$, higher $\omega^{+}$, and higher $f$ than CTH-21.

\section{Conclusions}

The methodology employed in this study with the M06 functional and the 6-31G(d) and 6-311G(d) basis sets showed good results. The chemical reactivity parameters were in agreement with the energy levels and HOMO/LUMO orbital densities. It can be a good and fast methodology to study a group of candidate molecules as photosensitizers, allowing one to work with a big group of molecules and leave a smaller group for more intensive study. Molecules with better photophysical properties were obtained by increasing the thiophene and/or thiazole units in the $\pi$-bridge. The CTH-122 molecule can be considered the best dye when considering all studies, which results in a DSSC with a higher efficiency; however, CTH222 showed very similar properties to CTH-122. Regarding the molecules with two units, the best was CTH-22 (using thiazole units instead of thiophene units), but CTH-12 had similar properties. Hence, using a combination of thiophenes and thiazoles in the $\pi$-bridge may be a good idea. 


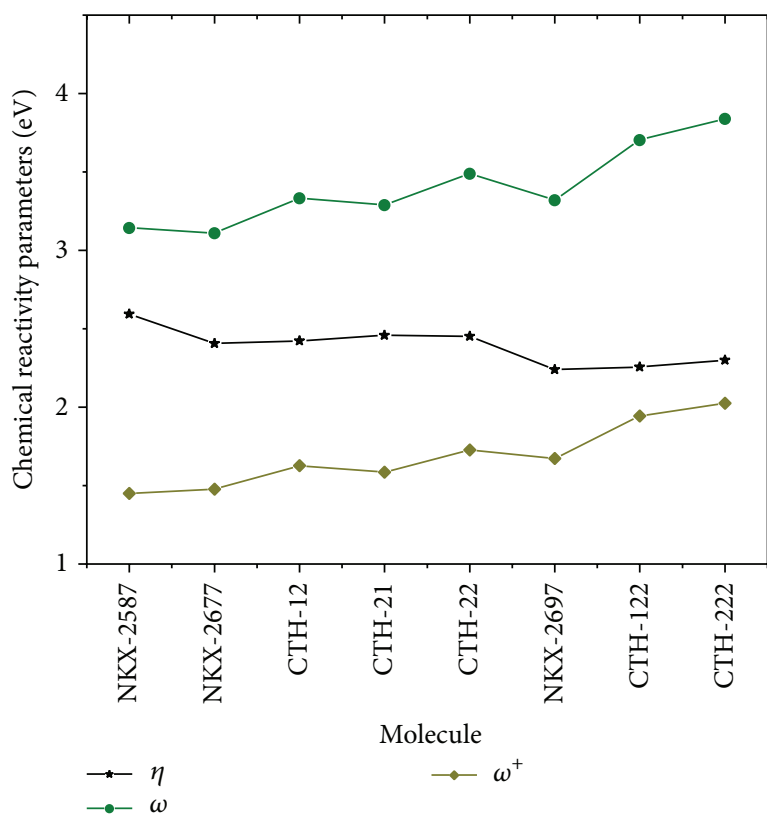

(a)

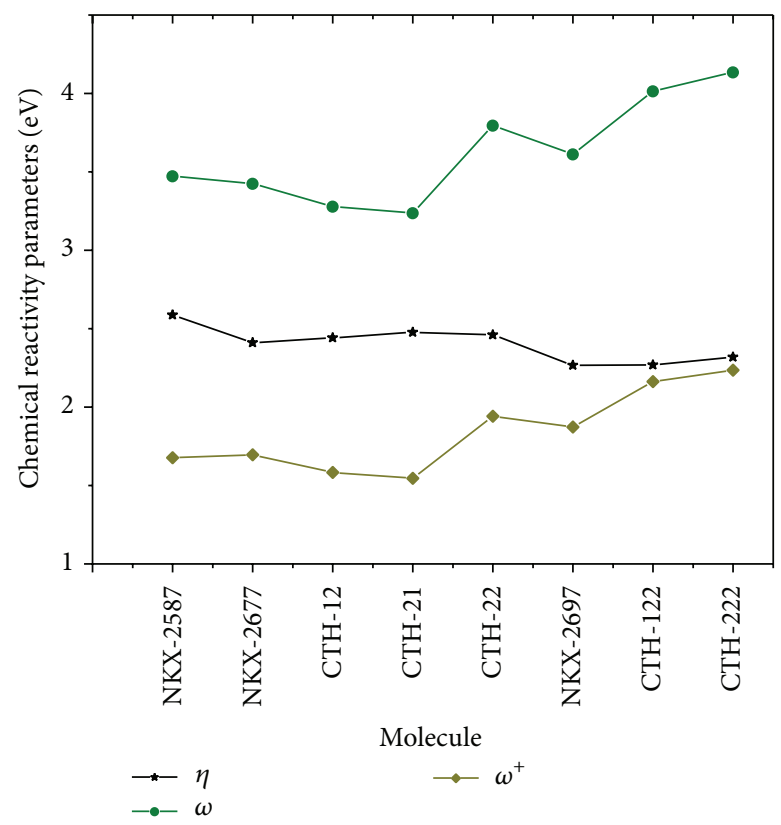

(b)

FIGURE 5: Chemical hardness, electrophilicity index, and electroaccepting power of coumarin dyes using the M06 functional with the basis sets: (a) 6-31G(d) and (b) 6-311G(d).

\section{Disclosure}

Daniel Glossman-Mitnik is a researcher of CIMAV and CONACYT. Jesús Baldenebro-López is a professor and researcher at the UAS and CONACYT.

\section{Conflict of Interests}

The authors declare that there is no conflict of interests regarding the publication of this paper.

\section{Acknowledgments}

This work was supported by the Consejo Nacional de Ciencia y Tecnología (CONACYT) and Centro de Investigación en Materiales Avanzados, S.C. (CIMAV) and the Universidad Autónoma de Sinaloa (UAS). Rody Soto-Rojo gratefully acknowledges a fellowship from CONACYT.

\section{References}

[1] B. O’Regan and M. Grätzel, "A low-cost, high-efficiency solar cell based on dye-sensitized colloidal $\mathrm{TiO}_{2}$ films," Nature, vol. 353, no. 6346, pp. 737-740, 1991.

[2] M. Grätzel, "Dye-sensitized solar cells," Journal of Photochemistry and Photobiology C: Photochemistry Reviews, vol. 4, no. 2, pp. 145-153, 2003.

[3] M. K. Nazeeruddin, A. Kay, I. Rodicio et al., "Conversion of light to electricity by cis-X2bis $\left(2,2^{\prime}\right.$-bipyridyl- $4,4^{\prime}$ dicarboxylate)ruthenium(II) charge-transfer sensitizers (X = Cl-, Br-, I-, CN-, and SCN-) on nanocrystalline $\mathrm{TiO}_{2}$ electrodes," Journal of the American Chemical Society, vol. 115, no. 14, pp. 6382-6390, 1993.
[4] M. K. Nazeeruddin, P. Péchy, and M. Grätzel, "Efficient panchromatic sensitization of nanocrystalline $\mathrm{TiO}_{2}$ films by a black dye based on a trithiocyanato-ruthenium complex," Chemical Communications, no. 18, pp. 1705-1706, 1997.

[5] M. K. Nazeeruddin, F. De Angelis, S. Fantacci et al., "Combined experimental and DFT-TDDFT computational study of photoelectrochemical cell ruthenium sensitizers," Journal of the American Chemical Society, vol. 127, no. 48, pp. 16835-16847, 2005.

[6] A. Hagfeldt, G. Boschloo, L. Sun, L. Kloo, and H. Pettersson, "Dye-sensitized solar cells," Chemical Reviews, vol. 110, no. 11, pp. 6595-6663, 2010.

[7] D. P. Hagberg, T. Marinado, K. M. Karlsson et al., "Tuning the HOMO and LUMO energy levels of organic chromophores for dye sensitized solar cells," The Journal of Organic Chemistry, vol. 72, no. 25, pp. 9550-9556, 2007.

[8] K. Hara, Z.-S. Wang, T. Sato et al., "Oligothiophene-containing coumarin dyes for efficient dye-sensitized solar cells," The Journal of Physical Chemistry B, vol. 109, no. 32, pp. 15476-15482, 2005.

[9] Z.-S. Wang, Y. Cui, Y. Dan-oh, C. Kasada, A. Shinpo, and K. Hara, "Thiophene-functionalized coumarin dye for efficient dye-sensitized solar cells: electron lifetime improved by coadsorption of deoxycholic acid," The Journal of Physical Chemistry C, vol. 111, no. 19, pp. 7224-7230, 2007.

[10] W. Zeng, Y. Cao, Y. Bai et al., "Efficient dye-sensitized solar cells with an organic photosensitizer featuring orderly conjugated ethylenedioxythiophene and dithienosilole blocks," Chemistry of Materials, vol. 22, no. 5, pp. 1915-1925, 2010.

[11] M. Zhang, Y. Wang, M. Xu, W. Ma, R. Li, and P. Wang, "Design of high-efficiency organic dyes for titania solar cells based on the chromophoric core of cyclopentadithiophenebenzothiadiazole," Energy \& Environmental Science, vol. 6, no. 10, pp. 2944-2949, 2013. 
[12] K. Kakiage, Y. Aoyama, T. Yano et al., "An achievement of over 12 percent efficiency in an organic dye-sensitized solar cell," Chemical Communications, vol. 50, no. 48, pp. 6379-6381, 2014.

[13] C.-R. Zhang, Z.-J. Liu, Y.-H. Chen et al., "DFT and TD-DFT study on structure and properties of organic dye sensitizer TASt-CA," Current Applied Physics, vol. 10, no. 1, pp. 77-83, 2010.

[14] R. Sánchez-de-Armas, J. Oviedo, M. Á. San Miguel, and J. F. Sanz, "Direct vs indirect mechanisms for electron injection in dye-sensitized solar cells," The Journal of Physical Chemistry C, vol. 115, no. 22, pp. 11293-11301, 2011.

[15] J. Zhang, Y.-H. Kan, H.-B. Li, Y. Geng, Y. Wu, and Z.-M. Su, "How to design proper $\pi$-spacer order of the D- $\pi$-A dyes for DSSCs? A density functional response," Dyes and Pigments, vol. 95, no. 2, pp. 313-321, 2012.

[16] R. Sánchez-De-Armas, M. Á. San Miguel, J. Oviedo, and J. F. Sanz, "Coumarin derivatives for dye sensitized solar cells: a TDDFT study," Physical Chemistry Chemical Physics, vol. 14, no. 1, pp. 225-233, 2012.

[17] J. Zhang, H.-B. Li, Y. Geng et al., "Modification on C219 by coumarin donor toward efficient sensitizer for dye sensitized solar cells: a theoretical study," Dyes and Pigments, vol. 99, no. 1, pp. 127-135, 2013.

[18] J. Kim, H.-S. Shim, H. Lee, M.-S. Choi, J.-J. Kim, and Y. Seo, "Highly efficient vacuum-processed organic solar cells containing thieno[3,2-b ]thiophene-thiazole," The Journal of Physical Chemistry C, vol. 118, no. 22, pp. 11559-11565, 2014.

[19] R. Menzel, D. Ogermann, S. Kupfer et al., "4-Methoxy-1,3thiazole based donor-acceptor dyes: characterization, X-ray structure, DFT calculations and test as sensitizers for DSSC, Dyes and Pigments, vol. 94, no. 3, pp. 512-524, 2012.

[20] W. Zhang, Q. Feng, Z.-S. Wang, and G. Zhou, "Novel thiazolo[5,4-d] thiazole-based organic dyes for quasi-solid-state dye-sensitized solar cells," Chemistry-An Asian Journal, vol. 8, no. 5, pp. 939-946, 2013.

[21] A. Dessi, M. Calamante, A. Mordini et al., "Thiazolo[5,4d]thiazole-based organic sensitizers with strong visible light absorption for transparent, efficient and stable dye-sensitized solar cells," RSC Advances, vol. 5, no. 41, pp. 32657-32668, 2015.

[22] Y. Zhao and D. G. Truhlar, "The M06 suite of density functionals for main group thermochemistry, thermochemical kinetics, noncovalent interactions, excited states, and transition elements: two new functionals and systematic testing of four M06-class functionals and 12 other functionals," Theoretical Chemistry Accounts, vol. 120, no. 1-3, pp. 215-241, 2008.

[23] R. G. Parr and R. G. Pearson, "Absolute hardness: Companion parameter to absolute electronegativity," Journal of the American Chemical Society, vol. 105, no. 26, pp. 7512-7516, 1983.

[24] J. L. Gázquez, A. Cedillo, and A. Vela, "Electrodonating and electroaccepting powers," The Journal of Physical Chemistry A, vol. 111, no. 10, pp. 1966-1970, 2007.

[25] M. Cossi and V. Barone, "Time-dependent density functional theory for molecules in liquid solutions," The Journal of Chemical Physics, vol. 115, no. 10, pp. 4708-4717, 2001.

[26] R. Improta, V. Barone, G. Scalmani, and M. J. Frisch, "A statespecific polarizable continuum model time dependent density functional theory method for excited state calculations in solution," The Journal of Chemical Physics, vol. 125, Article ID 054103, 2006.

[27] S. I. Gorelsky, SWizard Program, University of Ottawa, Ottawa, Canada, 2013.
[28] S. I. Gorelsky and A. B. P. Lever, "Electronic structure and spectra of ruthenium diimine complexes by density functional theory and INDO/S. Comparison of the two methods," Journal of Organometallic Chemistry, vol. 635, no. 1-2, pp. 187-196, 2001.

[29] M. M. Francl, W. J. Pietro, W. J. Hehre et al., "Self-consistent molecular orbital methods. XXIII. A polarization-type basis set for second-row elements," The Journal of Chemical Physics, vol. 77, no. 7, pp. 3654-3665, 1982.

[30] V. A. Rassolov, M. A. Ratner, J. A. Pople, P. C. Redfern, and L. A. Curtiss, " $6-31 G^{*}$ basis set for third-row atoms," Journal of Computational Chemistry, vol. 22, no. 9, pp. 976-984, 2001.

[31] R. Krishnan, J. S. Binkley, R. Seeger, and J. A. Pople, "Selfconsistent molecular orbital methods. XX. A basis set for correlated wave functions," The Journal of Chemical Physics, vol. 72, no. 1, pp. 650-654, 1980.

[32] E. Cancès, B. Mennucci, and J. Tomasi, "A new integral equation formalism for the polarizable continuum model: theoretical background and applications to Isotropic and anisotropic dielectrics," The Journal of Chemical Physics, vol. 107, no. 8, pp. 3032-3041, 1997.

[33] M. J. Frisch, G. W. Trucks, H. B. Schlegel et al., Gaussian 09, Revision D.01, Gaussian, Wallingford, Conn, USA, 2009.

[34] K. Hara, M. Kurashige, Y. Dan-Oh et al., "Design of new coumarin dyes having thiophene moieties for highly efficient organic-dye-sensitized solar cells," New Journal of Chemistry, vol. 27, no. 5, pp. 783-785, 2003.

[35] P. Dev, S. Agrawal, and N. J. English, "Determining the appropriate exchange-correlation functional for time-dependent density functional theory studies of charge-transfer excitations in organic dyes," The Journal of Chemical Physics, vol. 136, no. 22, Article ID 224301, 2012.

[36] M. A. Green, Solar Cells: Operating Principles, Technology, and System Applications, Edited by U. O. N. S. Wales, Prentice-Hall, Englewood Cliffs, NJ, USA, 1982.

[37] P. Shen, Y. Liu, X. Huang et al., "Efficient triphenylamine dyes for solar cells: effects of alkyl-substituents and $\pi$-conjugated thiophene unit," Dyes and Pigments, vol. 83, no. 2, pp. 187-197, 2009.

[38] X. Lu, S. Wei, C.-M. L. Wu, S. Li, and W. Guo, "Can polypyridyl $\mathrm{Cu}(\mathrm{I})$-based complexes provide promising sensitizers for dyesensitized solar cells? A theoretical insight into $\mathrm{Cu}(\mathrm{I})$ versus $\mathrm{Ru}(\mathrm{II})$ sensitizers," The Journal of Physical Chemistry C, vol. 115, no. 9, pp. 3753-3761, 2011.

[39] J. Wang, M. Li, D. Qi, W. Shen, R. He, and S. H. Lin, "Exploring photophysical properties of metal-free coumarin sensitizers: an efficient strategy to improve the performance of dye-sensitized solar cells," RSC Advances, vol. 4, no. 96, pp. 53927-53938, 2014.

[40] J. Martínez, "Local reactivity descriptors from degenerate frontier molecular orbitals," Chemical Physics Letters, vol. 478, no. 4-6, pp. 310-322, 2009.

[41] R. Soto-Rojo, J. Baldenebro-López, and D. Glossman-Mitnik, "Study of chemical reactivity in relation to experimental parameters of efficiency in coumarin derivatives for dye sensitized solar cells using DFT,' Physical Chemistry Chemical Physics, vol. 17, no. 21, pp. 14122-14129, 2015.

[42] R. G. Parr, L. V. Szentpály, and S. Liu, "Electrophilicity index," Journal of the American Chemical Society, vol. 121, no. 9, pp. 1922-1924, 1999. 

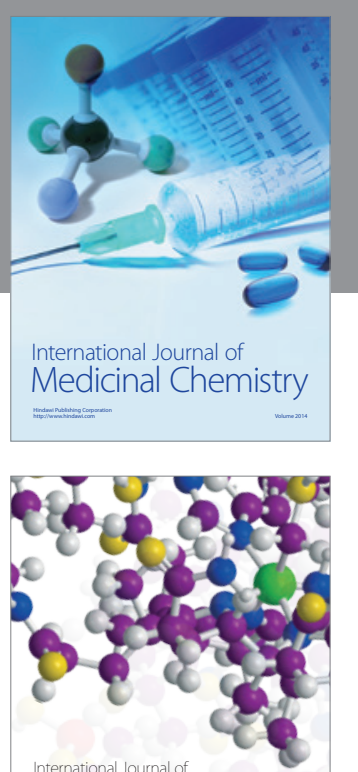

Carbohydrate Chemistry

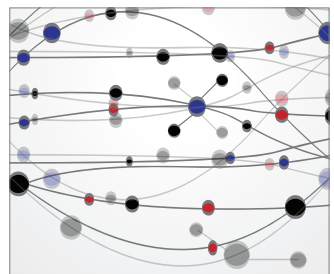

The Scientific World Journal
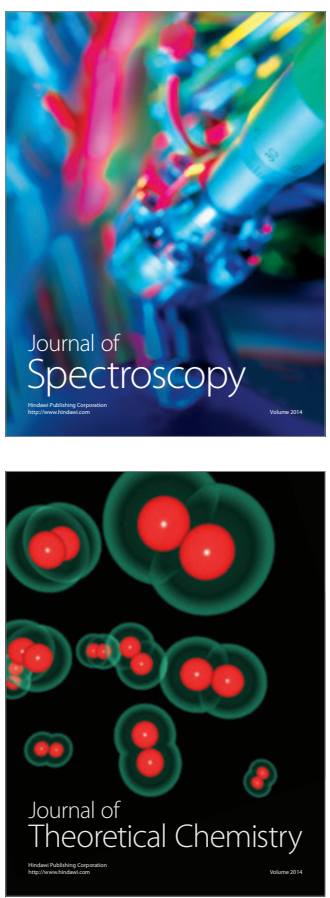
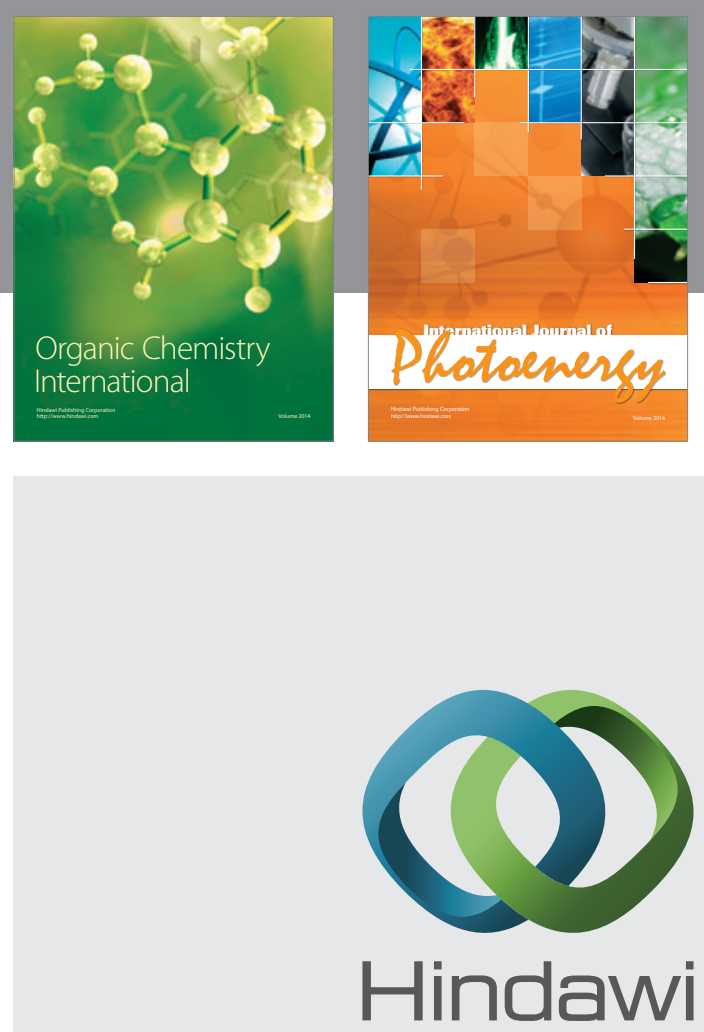

Submit your manuscripts at

http://www.hindawi.com

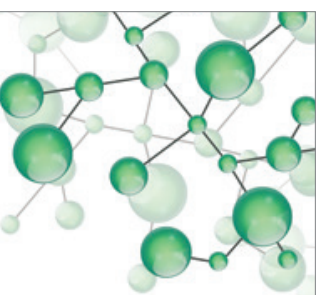

International Journal of

Inorganic Chemistry

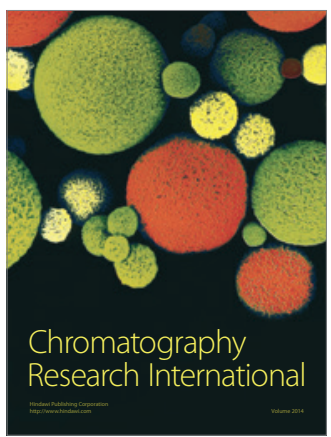

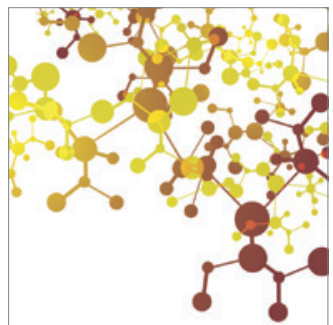

Applied Chemistry
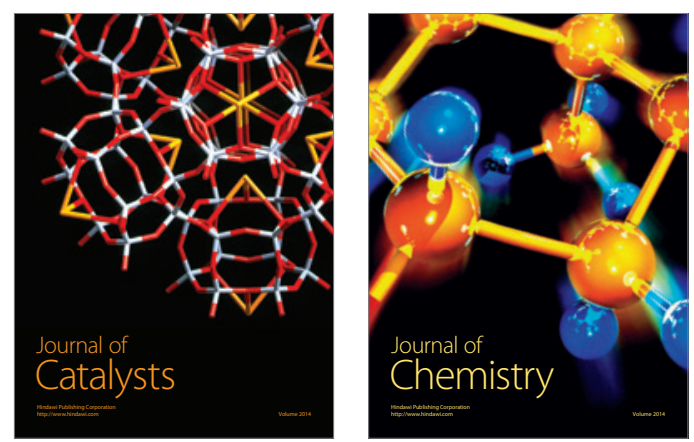
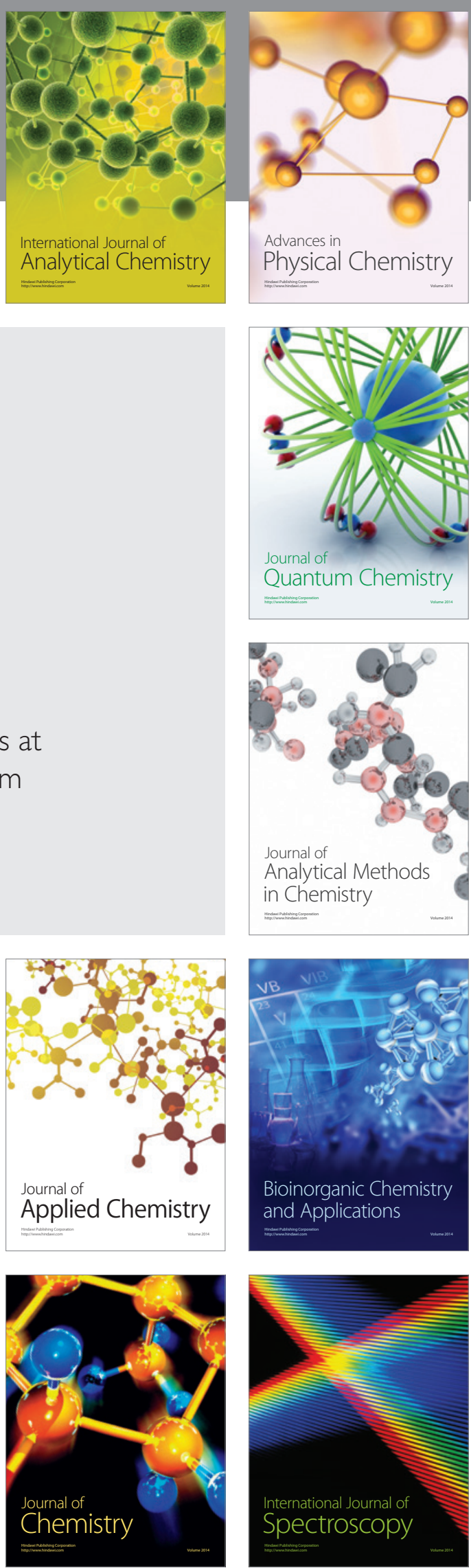